\title{
GOVERNANÇA PÚBLICA PARA O ENFRENTAMENTO DAS MUDANÇAS CLIMÁTICAS EM CURITIBA E ENTORNO
}

\author{
Myrian Del Vecchio de Lima * \\ Claudia Cristina Lopes Machado ** \\ João Batista Alves *** \\ Rafaela Antunes Fortunato ****
}

public governance to tackle climate change in Curitiba and the surrounding area

\begin{abstract}
Resumo
Este texto apresenta uma síntese sobre a discussão do processo da governança socioambiental climática em âmbito local, sem deixar de lado aspectos globais e nacionais. Nestas escalas emergiram, nas últimas décadas, novos atores e novas formas de gestão, tanto no setor público e privado quanto no terceiro setor e em coletivos de ação. O conteúdo explicita uma análise crítica do processo de governança local — nos municípios de Curitiba, capital do estado do Paraná, e de seu entorno, Fazenda Rio Grande e Araucária especificamente sobre o segmento ligado às instituições públicas. A argumentação foi construída a partir de um mapeamento sobre as ações e políticas de vários órgãos governamentais, estaduais e municipais. Privilegiam-se nessa análise, as categorias de enfrentamento, prevenção e mitigação aos possíveis desastres e perigos associados às condições climáticas futuras e suas inserções no âmbito da Política Estadual para as Mudanças Climáticas, documento que direciona a governança estadual na área.
\end{abstract}

Palavras-chaves: Eventos climáticos; Governança socioambiental; Políticas públicas; Riscos e perigos.

\begin{abstract}
This paper presents an overview of the discussion on the process of socio-environmental climate governance at the local level, without neglecting global and national aspects. In recent decades, new actors and new forms of management have emerged on these scales in the public and private sector, as well as the third sector and collective action. The study makes a critical analysis of the local governance process in the municipalities of Curitiba, the state capital of Paraná and its surroundings, in Fazenda Rio Grande and Araucária, specifically regarding the segment connected to public institutions. The argument was constructed from a mapping of the policies and actions of various state and municipal government agencies. In this analysis preference is given to the aspects of tackling, preventing and mitigating possible disasters and hazards associated with future climate conditions and their insertion into the State Policy on Climate Change, the document that directs state governance in the area.
\end{abstract}

Key words: Climatic events; Environmental governance; Public policies; Risks and hazards.

\begin{abstract}
Résumé
Ce document présente une discussion sur le processus de gouvernance environnementale climatique au niveau local, sans pour autant négliger les aspects mondiaux et nationaux. Dans ces échelles ont émergé, au cours des dernières décennies, de nouveaux acteurs et de nouvelles formes de gestion dans les secteurs public, privé, le tiers secteur et l'action collective. Le contenu met en évidence une analyse critique du processus de gouvernance locale - dans la ville de Curitiba (Brésil) et ses environs, notamment aux communes de Fazenda Rio Grande et d'Araucaria - en particulier sur le segment relié aux institutions publiques. L'argument a été construit à partir d'une cartographie des actions et des politiques de divers organismes gouvernementaux, de l'État du Paraná et des trois municipalités. L'analyse prend en compte principalement les catégories de luttes, de prévention et d'atténuation des catastrophes et des risques associés à des conditions climatiques futures et leurs insertions dans la politique de l'État sur le changement climatique.
\end{abstract}

Mots-Clés: Événements climatiques; Gouvernance environmental; Politiques publiques; Risques et catastrophes.

(*) Profa. Dra. da Universidade Federal do Paraná - Rua Bom Jesus, 650, CEP: 80035010, Curitiba (PR), Brazil. Tel: (+55 41)33132005 - myriandel@gmail.com

(**) Doutora pela Universidade Federal do Paraná) - Rua Bom Jesus, 650, CEP: 80035010, Curitiba (PR), Brazil. Tel: (+55 41) 33132005 - - contato@claudiamachado.com.br

(***) Prof. Dr. da Universidade Federal de Campina Grande) - Avenida Universitária, s/n, CEP: 58708110, Patos (PB), Brazil. Tel: (+55 83) 34239712 - alvesjb@uol.com.br

(****) Profa. Dra. da Universidade Tecnológica Federal do Paraná) - Av. Sete de Setembro, 3165, CEP: 80230-901, Curitiba (PR), Brazil. Tel: (+55 41) 33104470 - refortunato@utfpr.edu.br 
LIMA, M. D. V.; MACHADO, C. C. L.; ALVES, J. B.; FORTUNATO, R. A.

\section{INTRODUÇÃO}

As mudanças climáticas globais têm se destacado nas últimas décadas entre os temas ambientais mais polêmicos, com repercussões científicas, políticas, econômicas, culturais, midiáticas e socioambientais, nas mais diferentes esferas. De fato, no âmbito ambiental, foi o tema mais recorrente, internacionalmente, de meados dos anos 1980 aos dias atuais e produziu um rol de estudos, indicadores e projeções de cenários que tiveram como ponto de partida, em termos de organização político-científica, a criação do IPCC (Intergovernamental Panel on Climate Change), em 1988, com uma proposta de governança internacional sobre a questão, formalizada na Conferência Mundial das Nações Unidas para o Meio Ambiente e Desenvolvimento, Rio-92 .

Um conjunto representativo de cientistas de todo o mundo tem afirmado, por intermédio do IPCC, em especial a partir do Relatório 4 (IPCC, 2009), que as temperaturas médias do planeta aumentaram cerca de $1,5^{\circ} \mathrm{C}$ nos dois últimos séculos, e que ocorrerá uma intensificação da ordem aproximada de $2^{\circ}$ a $6^{\circ} \mathrm{C}$ no século XXI. Entre as afirmações do Painel, interessa aqui, a de que os moradores das grandes cidades serão os mais afetados por essas mudanças. O Relatório de Avaliação Nacional de Mudanças Climáticas (Sumário Executivo PBMC, 2012), apresentado pelo Painel Brasileiro de Mudanças Climáticas, em junho de 2012, prevê intensificação da seca no Nordeste e no Norte e aumento de chuvas no Sul e Sudeste. Conforme o estudo, assinado por 128 pesquisadores de diversas universidades e institutos de pesquisa brasileiros, os biomas da Amazônia e da Caatinga serão extremamente ameaçados até o final do século, enquanto na Mata Atlântica do Sudeste e nos Pampas, do Sul, haverá um aumento de até 30\% nas chuvas.

As cidades brasileiras, marcadas pelo fenômeno da "urbanização corporativa" (SANTOS, 1993), terão seus riscos agravados, conforme a lógica mundial que, desde o final do século XX, apresenta o fenômeno da concentração demográfica mundial em aglomerados urbanos, com um processo de urbanização acelerada, tornando cada vez maior o número de áreas e populações vulneráveis a riscos e desastres socioambientais de origem natural ou tecnológica.

Esta situação, que se agrava nas franjas metropolitanas e regiões periféricas das cidades, como é o caso da Região Metropolitana de Curitiba (RMC), configura um ambiente propício, em função de sua própria vulnerabilidade, aos possíveis efeitos prejudiciais das mudanças climáticas aceleradas, como sinalizam as modelizações de cenários futuros sobre o clima; são exemplos de possíveis efeitos indesejáveis o aumento de temporais com inundações e enchentes, o recrudescimento de doenças tropicais, as mudanças de hábitos e culturas, entre outros.

Diante desse quadro, considerado por muitos como preocupante, e por alguns como alarmista, as abordagens sobre o tema têm sido as mais diversas, dividindo-se entre aquelas utilizadas pelos estudiosos que estabelecem o agravamento das mudanças climáticas de origem antropogênica e os pesquisadores "céticos", que relativizam a influência do ser humano e seu sistema sócio-produtivo no processo.

Esse artigo que aborda a governança socioambiental, em especial a governança climática, recorre às visões mais gerais de Viola, Barros-Platiau e Leis (2008) e Borsato (2012), para chegar à análise das ações e políticas públicas de enfrentamento da questão na Região Metropolitana de Curitiba/PR.

O texto apresenta um inventário de ações das instituições públicas de três municípios dessa região: seu polo, a cidade de Curitiba, e os municípios de Araucária e de Fazenda Rio Grande, que integram a chamada Região Metropolitana (RM). No âmbito desse aglomerado urbano, inúmeros autores - entre os quais Fritzsons at. al. (2001), Mendonça (2004), Francisco (2005), Lima (2008), Hummel (2009) e Bosa e Lombardi (2011) — têm relatado problemas socioambientais ligados a desastres naturais ou tecnológicos. Neste sentido, alterações climáticas podem intensificar os problemas descritos na literatura.

Para realizar o inventário proposto, elegeram-se algumas categorias para levantamento de dados, a partir do rol de instituições públicas identificadas nos três municípios: as prefeituras, se- 
cretarias estaduais do meio ambiente e a Defesa Civil dos municípios e do Estado, além de outros órgãos públicos que, de alguma forma, se relacionam com o tema. Para permitir o entendimento da lógica das políticas públicas que definem as ações em andamento ou em proposição, foram incluídos no levantamento o Governo do Estado do Paraná e secretarias afins ao tema, com destaque para a Secretaria Estadual do Meio Ambiente e seus programas, incluindo aí o Fórum Paranaense de Mudanças Climáticas Globais.

Saliente-se que, no Paraná, o Fórum foi precursor, no âmbito do setor público, dos debates sobre o tema e nele se iniciaram as discussões para a implementação da Coordenadoria de Mudanças Climáticas, em 2007, bem como para a elaboração e criação da Lei Estadual de Mudanças Climáticas, que estabeleceu a Política Estadual sobre Mudança do Clima, documento básico para se iniciar essa pesquisa.

Preliminarmente, utilizou-se a busca de publicações científicas e a leitura das informações disponíveis em sites eletrônicos das instituições públicas sobre o tema, além de documentos impressos. Em seguida, elaborou-se um roteiro para entrevistas com os representantes dos órgãos relacionados, gravadas digitalmente e anotadas; algumas entrevistas foram feitas por email. Os resultados foram inseridos em planilha organizada em torno de categorias que serviram para identificar se as ações eram de enfrentamento, mitigação e adaptação, desdobradas em subcategorias analíticas descritas mais adiante.

No período de pesquisa de campo (2012-2014), boa parte das ações elencadas se encontrava em fase de proposições ou de implantação; há pouca ênfase na prevenção para o enfrentamento dos problemas decorrentes das mudanças climáticas; a maioria das ações propostas parece ter sido arrolada para cumprir recomendações de governança internacional e nacional sobre o tema, no sentido de "cima para baixo" (top down), conforme o entendimento de Viola, Barros-Platiau e Leis (2008). A inclusão dessas medidas em políticas públicas locais e regionais garante recursos de várias procedências para financiamentos, além de fomentar a organização de um mercado, como o de certificações, incluindo profissionais voltados para a gestão público-privada das mudanças climáticas; entretanto, o espaço para a chamada governança de risco (Renn, 2008), espaço onde se enquadra o tema em estudo, parece ainda carecer de práticas que favoreçam a participação ativa e construtiva dos diferentes atores sociais envolvidos em processos decisórios.

\section{DAS NOVAS GOVERNANÇAS À GOVERNANÇA CLIMÁTICA E SEUS CONCEITOS}

A crise ambiental no mundo contemporâneo emerge em paralelo a uma crise de governança, visibilizadas quase que simultaneamente nas últimas décadas do século XX. Um dos conceitos de governança escolhido para este estudo é aquele desenvolvido por Santos (1997):

Governança refere-se a padrões de articulação e cooperação entre atores sociais e políticos e arranjos institucionais que coordenam e regulam transações dentro e através das fronteiras do sistema econômico, incluindo aí não apenas os mecanismos tradicionais de agregação e articulação de interesses, tais como os partidos políticos e grupos de pressão, como também redes sociais informais (de fornecedores, famílias, gerentes), hierarquias e associações de diversos tipos (SANTOS, 1997, p.342).

No panorama de crises de fin de siécle, que adentrou o segundo milênio, surgiram novas formas de governança em todos os setores e sobre os mais diversos cenários, nos âmbitos global, nacional e local, para além do Estado e de suas crises que se avolumaram nos anos 1980-1990, com o impacto da visão neoliberal sobre a economia e a política. Estas "novas governanças" se materializaram no setor privado-empresarial e avançaram sobre áreas antes exclusivas de gerenciamento do poder público (SOUSA SANTOS, 2005); também surgiram como alternativas de gestão participativa, mobilizadora, cidadã, que passaram a construir, no segundo milênio, resistências aos modos hegemônicos de gestão em todos os setores sociais - técnicos, administrativos, políticos, econômicos, 
jurídico-legal, de assistência e saúde, de conhecimento, por meio da participação social.

Borsato (2012) reporta-se à Wapner (1996), ao assinalar essa ampliação do processo de governança, inclusive o da área ambiental, considerado como uma nova governança, que passa a inserir novos atores e mecanismos de participação na arena global, repleta de interesses públicos, privados e cidadãos:

A compreensão do processo de governança amplia o debate sobre os mecanismos de participação dos atores no cenário internacional, envolvendo segmentos diversos, tais como o sistema das Nações Unidas, regimes internacionais setoriais, atores distintos que representam o mercado, e a crescente participação de setores da sociedade civil, como as ONGs, que cada vez mais assumem um papel estratégico na implementação de políticas ambientais no âmbito local, regional, nacional e global; contribuindo para a conformação da política cívica mundial. (BORSATO, 2012, p.20).

Foros internacionais, como a Organização das Nações Unidas (ONU) e seus diversos órgãos, gestores de crises de interesse mundial, ilustram o conceito de governança global, termo cunhado nas áreas de direito e das relações internacionais. O conceito, de acordo com Barros-Platiau et al. (2004), diz respeito às formas de influência e ação de atores coletivos não estatais nos processos políticos e de elaboração de normas jurídicas internacionais, expressos por estas instituições e outros regimes, que atuam no debate e regulação dos desafios contemporâneos internacionais. Esses órgãos coletivos da sociedade global procuram, graças ao seu reconhecimento e representatividade nas diferentes esferas de poder político, econômico, cultural e científico, transferir suas recomendações, diretrizes e propostas de ação, pactuadas em grandes eventos transnacionais, aos governos dos países signatários, por meio de legislações específicas e políticas públicas.

Já a governança ambiental no mundo e nos países tem se pautado pela criação de formas específicas de articulações e cooperação entre diversos atores sociais, em especial aqueles do terceiro setor, que fortalecido, no âmbito da crise do Estado, se envolve na elaboração de novos instrumentos de gestão ambiental voltadas para necessidades e desafios em manter ou conquistar a qualidade de vida no binômio natureza-sociedade, em um cenário de globalização acelerada de capitalismo de mercado, que promove injustiças sociais e injustiças ambientais. (BORSATO, 2012) No que tange especificamente à governança climática, é preciso destacar que a questão por muitos anos restrita à esfera científica, - ao agregar cada vez mais informações e leituras que permitiram a projeção de cenários preocupantes em termos de riscos e perigos para as populações do planeta - foi se deslocando, em especial a partir da Convenção-Quadro das Nações Unidas sobre Mudança do Clima, em 1992, para o âmbito do "fomento e suporte a políticas públicas que contemplassem a necessidade de estabilizar as alterações do clima" (PINTO, 2012, p.12). A partir dessa data, o processo de governança global com relação à questão se acelera, quando 166 nações signatárias da convenção citada, universo posteriormente ampliado, concordaram em controlar e comunicar anualmente suas emissões de gases de efeito estufa (GEEs) à comunidade internacional, em foros apropriados.

Na sequência do processo de governança capitaneado pela ONU, o tratado internacional Protocolo de Kyoto estabeleceu metas mundiais de redução dessas emissões para os países desenvolvidos. É quando se explicitam os conflitos entre interesses econômicos e ambientais, claramente expressos pela não adesão dos Estados Unidos ao protocolo. A racionalidade moderna, na qual sempre prevalece a razão econômica, contrapõe-se aos preceitos da chamada racionalidade ambiental preconizada por Leff (2006), que a concebe como uma nova lógica engendrada por uma mudança de paradigmas necessária para equilibrar os conflitos sociedade-natureza.

Para melhor entendimento da questão da governança climática é preciso integrar a ela o conceito de segurança climática, considerado por muitos autores ainda incipiente, em elaboração a partir de 2006, com relação à preocupação cada vez maior do problema do aquecimento global entre o rol de problemas ambientais do planeta. A manutenção da estabilidade do clima global, que garantiu o desenvolvimento 
civilizatório desde a última Era Glacial, busca a mitigação dos efeitos do aquecimento do planeta e a adaptação a um clima mais quente com fenômenos climáticos extremos mais frequentes

A relação entre governança climática e segurança climática se estabelece em termos do caráter mais objetivo (hard) da relação entre sociedade humana e circulação atmosférica, estabelecendo limites para além dos quais não é possível pensar em termos de adaptação. A segurança climática implica uma clara escolha da humanidade pela prioridade da mitigação do aquecimento global sobre a adaptação (VIOLA et al., 2008, p.8).

A governança relativa ao clima, de acordo com os autores acima citados, é "marcada por negociações oficiais que constroem lentamente um regime sobre o clima.”. (VIOLA et al., 2008, p.7). Para esses autores, tal governança tem apresentado, até o momento, "resultados decepcionantes em face dos cenários futuros anunciados e com pouca participação de atores não-estatais.". (VIOLA et al., 2008, p.7). Eles ainda destacam, numa visão crítica própria dos países em desenvolvimento e do Sul, visão também compartilhada pela diplomacia brasileira que, "governança ambiental corresponde a uma agenda imposta por alguns países ricos e europeus, como Reino Unido, França e Alemanha, ao resto do mundo.”. (VIOLA et al., 2008, p.7).

Nesse cenário, os governos de centenas de países passaram a inserir uma agenda de recomendações, diretrizes e ações em suas políticas públicas, como forma de enfrentamento das questões socioambientais, criando foros nacionais de governança ambiental, em áreas específicas. Esse tipo de governança (de cima para baixo ou top down) é definida por Viola et al. (2008, p.6), como a que ocorre quando as autoridades públicas tornam-se mais responsáveis e transparentes aos olhos da sociedade: "Elas respondem à demanda por maior controle social e prestam contas aos outros atores sociais e internacionais em geral". A publicação de websites governamentais de informações sobre programas, legislação específica, prioridades e orçamento, a exemplo dos vários sites de órgãos de governo examinados nessa pesquisa, ilustram essa forma de governança. Já a governança de baixo para cima (botton up) configura-se quando "atores não-estatais levam possíveis soluções de um problema às autoridades públicas ou o resolvem sozinhos.”. (VIOLA et al., 2008, p.6).

Sob o ponto de vista de Pittock (2005), a governança somente será efetiva se os diversos atores sociais atuarem em conjunto na busca por resultados positivos nas políticas relacionadas às mudanças climáticas. Assim, a sociedade civil - empresários, ambientalistas, cientistas e outros grupos - devem empregar esforços conjuntos de inovação, visando reduzir a emissão de carbono e realizar uma transição gradativa de toda a sociedade para uma economia de baixo uso do carbono.

Por sua vez, Renn (2008), ao utilizar o conceito de governança de riscos — processo que deveria envolver representantes de todos os grupos sociais - entende a participação efetiva de todos os atores implicados/envolvidos, de forma ativa e construtiva, compondo um discurso que estabeleça a possibilidade da elaboração de um diálogo comum a respeito do risco a ser enfrentado e suas formas de gestão. É neste sentido que Di Giulio e Ferreira (2014) defendem que "em situações de risco associadas às mudanças climáticas e ambientais, ou potencializadas por esses fenômenos, a prática de um processo decisório mais aberto e participativo, que inclua as percepções, necessidades e interesses das comunidades afetadas, é relevante" (p. 33). Tais autoras entendem que pela complexidade e incertezas envolvidas nestes processos, as decisões regulatórias "não podem ser buscadas apenas no conhecimento técnico, elas devem incluir a participação dos stakeholders e envolver o público", (p. 33).

O recorte empírico deste artigo examina os processos de governança climática realizada por instituições públicas, a chamada top down. Giddens (2010, p.279) defende que a governança pública climática deverá "fomentar uma consciência mais generalizada da necessidade de ação". Para ele, o sucesso de políticas públicas na área depende da capacidade dos governos em "levar as pessoas a admitirem que os riscos são reais e prementes", de forma que, por meio de atitudes e práticas cotidianas, voltem-se à prevenção, mitigação e enfrentamento das emissões de gases e outras formas de aceleramento do aquecimento global antropogênico como fator de alteração do clima. 
Por seu turno, Pelling (2003) também defende a ampliação do leque de atores no processo de governança climática, em especial em áreas urbanas, ao afirmar a importância do estabelecimento de parcerias fortes entre comunidades locais e suas organizações de base internas, organizações governamentais e não governamentais externas, setores privados e entre os governos municipais e os governos estaduais/nacionais.

Assim, os espaços de governança se reproduzem, em termos de criação de legislação, políticas públicas, programas, medidas e ações, para os âmbitos estaduais/regionais/municipais, com a participação de fóruns e outros coletivos de ação que envolvam cidadãos mobilizados, como os comitês gestores, conselhos municipais, audiências públicas e fóruns representativos da sociedade civil específicos.

Ainda, como aporte teórico para iluminar a análise posterior aqui empreendida, é preciso assinalar os conceitos já apontados de prevenção, adaptação e mitigação (VEYRET, 2007; MARANDOLA, 2009) considerados pilares para a governança climática, tomados como riscos e vulnerabilidades aos quais a população e o meio ambiente estão expostos. Acrescente-se a eles, o conceito de resiliência (MARANDOLA, 2009 e PITTOCK, 2005), hoje apropriado pelas ciências socioambientais; e o de transformação, defendido pelo economista equatoriano Alberto Acosta (2013).

A "sociedade de risco" (BECK, 1997; GIDDENS, 1991), caracterizada por seu alto grau de reflexividade, apresenta em função de diversos fatores, uma percepção maior sobre o aumento da ocorrência dos problemas socioambientais e, como decorrência, a percepção de que é uma sociedade mais exposta aos riscos e vulnerabilidades. Entende-se que o risco (álea, perigo, ameaça) é construído socialmente e que "pela primeira vez a humanidade conheceu e realizou meios de sua própria destruição" (VEYRET, 2007, p. 15). A afirmação da autora, embora se refira exemplarmente aos riscos tecnológicos, pode ser relacionada também às mudanças climáticas intensificadas por atividades antropogênicas.

A vulnerabilidade, por sua vez, refere-se "à magnitude do impacto previsível de uma álea sobre os alvos" (VEYRET, 2007, p. 24), podendo ser humana, socioeconômica e ambiental. Pode ainda se referir ao grau de exposição ou suscetibilidade aos riscos e desastres, às "fragilidades e capacidades das pessoas e sistemas de passar pela experiência de perigo" (MARANDOLA JR. 2009, p.37). Pode-se pensar o evento de risco, realizado ou não, do ponto de vista de "como grupos populacionais, lugares ou instituições poderão suportar os impactos do perigo, absorvendo os impactos (vulnerabilidade), recuperando-se ao estado do pré-evento (resiliência) ou alterando comportamentos, normas ou o próprio ordenamento territorial (adaptação)". (MARANDOLA JR, 2009, p.37, grifos do autor). A resiliência é entendida, portanto, como "a capacidade de um sistema para se adaptar às mudanças resultantes de uma crise e melhorar sua capacidade de resposta, tendo em vista catástrofes futuras.”, (VEYRET, 2007, p.43). A concepção de resiliência destes autores configura uma abertura, com novos significados do conceito que, em sua gênese na matemática, biologia e psicologia, trata da capacidade do retorno à situação antes do impacto. Para eles, a concepção de resiliência está próxima da concepção de adaptação.

Outro conceito trazido por Marandola Jr. (2009) é o de ajustamento que está associado à adaptação, porém, difere desta pelo fato de remeter também à mudança, mas de modo mais sutil, a curto e médio prazo, geralmente percebido e/ou estimulado no pré-evento. O ajustamento, todavia, não visa à transformação completa, e sim a pequenos ajustes nos processos, o que faz diferir este conceito daqueles de mitigação, estratégia de adaptação mais ampla, que se refere a existência de demanda existir um dano específico que deve ser mitigado.

Além da resiliência e adaptação, os riscos e vulnerabilidades decorrentes de problemas socioambientais, como as mudanças climáticas, podem, do ponto de vista da governança, ser enfrentados - e essa seria a forma mais racional e importante no processo em discussão - pela sua prevenção, tomando-se medidas que impeçam sua concretização como evento que resulte em perigo, riscos ou vulnerabilidade, possibilidade difundida na área ambiental pelo que se chama de princípio da 
precaução. Caso já em processo, as mudanças climáticas e seus efeitos também podem ser enfrentados por medidas e ações de mitigação.

Uma breve visão sobre as políticas públicas federais e do Estado do Paraná, que incidem sobre os municípios aqui envolvidos no âmbito da gestão das mudanças climáticas, permite verificar como a governança pública prevê formas de enfrentamento à questão, pelos entendimentos de prevenção, adaptação e mitigação.

\section{AS POLÍTICAS PÚBLICAS E AS MUDANÇAS CLIMÁTICAS}

Antes de abordar as políticas públicas federais e estaduais sobre mudanças climáticas, é importante acentuar o entendimento de Pittock (2005) de que os governos têm o dever de estabelecer padrões, metas e regras de comportamento equitativas no que tange às políticas relacionadas à área. Essa equidade nos países, entre países e entre gerações é que vai poder facilitar a realização dos objetivos dessas políticas, embora, seu sucesso dependa sempre da participação efetiva de toda a sociedade civil: empresas, consumidores, investidores e inovadores. Para o autor, políticas e leis só são eficazes se a sociedade civil quiser que elas funcionem e é crucial considerar a urgência das medidas e como elas podem ser bem sucedidas, evitando perigos e reduzindo os riscos dos desastres naturais relacionados às mudanças climáticas, tanto no futuro próximo quanto para as gerações futuras.

A Política Nacional de Mudanças Climáticas - PNMC (BRASIL, 2009) foi instituída pela Lei n. 12.187/2009, sancionada em 15/09/2010. Em seu artigo $12^{\circ}$, a Lei estabelece que para alcançar seus objetivos o país adotará como compromisso nacional voluntário, ações de mitigação das emissões de gases de efeito estufa, com vistas em reduzir entre 36,1\% e 38,9\% as emissões projetadas até 2020 .

Ao avaliar o quanto as iniciativas públicas estaduais e municipais estão conectadas entre si e com a política nacional, por meio de avaliação das diversas políticas públicas, Albuquerque (2012, p.96) afirma que "percebe-se que até o momento a constituição das legislações estaduais de mudanças climáticas tem ocorrido de forma autônoma e desconectada no país.”. A autora destaca que as políticas estaduais constituídas após a aprovação da política nacional "mantêm este padrão de não se alinhar a PNMC, com algumas exceções pontuais" (ALBUQUERQUE, 2012, p.96), conforme dados do Instituto Ethos, 2012. No documento "O desafio da harmonização das políticas públicas de mudanças climáticas", afirma-se: "Se por um lado, essa característica valoriza a iniciativa e a particularidade do processo em cada Estado, por outro, a ausência de coordenação e padronização pode implicar dificuldades para a governabilidade das políticas de mudanças climáticas estaduais". (FÓRUM CLIMA, 2012, p.16).

A Política Estadual de Mudanças Climáticas do Estado do Paraná - PEMC-PR (PARANÁ, 2012) instituída pela Lei 17.133, de 25/04/2012, norteia a elaboração de um Plano Estadual sobre Mudança do Clima, além de outros projetos, programas e ações na área, a maioria ainda em elaboração/implementação em 2013. Para os fins previstos na Lei Estadual explicita-se, além dos termos utilizados na política nacional (adaptação, efeitos adversos da mudança do clima, emissões, fonte, gases de efeito estufa, impacto, mitigação, mudança do clima, sumidouro, vulnerabilidade), a expressão Ações de Mitigação Nacionalmente Apropriadas (Nama), que procede do termo internacional Nationallity Appropriate Mitigation Actions, definida como medidas de mitigação adequadas a cada país em desenvolvimento, no contexto da sustentabilidade, com o apoio tecnológico, financeiro e de capacitação adequados, de maneira que possam ser mensurados, relatados e verificados (Art. $2^{\circ}$, I). Na legislação nacional, o termo é apenas citado. A lei estadual ainda explicita as expressões eventos climáticos extremos; inventário de emissões de gases de efeito estufa; e "sistema climático".

Em ambas as leis o entendimento de adaptação se refere às iniciativas e medidas para reduzir a vulnerabilidade dos sistemas naturais e humanos frente aos efeitos atuais e esperados da mudança do clima; assim, como o entendimento de mitigação é uniformizado, referindo-se às mudanças e 
substituições tecnológicas que reduzam o uso de recursos e as emissões por unidade de produção, bem como a implementação de medidas que reduzam as emissões de gases de efeito estufa e aumentem os sumidouros; a PEMC-PR estende o conceito de mitigação para o de ação de mitigação, ao utilizar a definição de Nama já citado. No entendimento de vulnerabilidade, no âmbito das duas leis, há apenas uma inversão na ordem das palavras que compõem o texto, que conduzem a um conceito similar (art. $2^{\circ}$ das respectivas leis).

Sobre o entendimento de mudança do clima, ambas as legislações adotam conceito semelhante, apenas com algumas diferenças de escolha de palavras e redação. Cita-se o texto da PNMC que entende ser mudança de clima aquela que possa ser direta ou indiretamente atribuída à atividade humana que altere a composição da atmosfera mundial e que se some àquela provocada pela variabilidade climática natural observada ao longo de períodos comparáveis.

As duas legislações têm como princípios (artigo $3^{\circ}$. em ambas as leis) a precaução e a prevenção, dentro da ampla condição de desenvolvimento sustentável, embora não seja definido o que significa cada um desses princípios e condições; são ainda adotados os princípios da participação cidadã e das responsabilidades comuns, porém diferenciadas. Na lei estadual, os princípios são apenas nominados, sem definições, o que pressupõe conhecimento do legislador/legislado: da proteção do sistema climático, da prevenção, de precaução, do poluidor-pagador, do conservador-beneficiário, do desenvolvimento sustentável, da informação, transparência e da participação, da responsabilidade comum, porém diferenciada; além de não definir, misturam-se princípios ligados a condições amplas como desenvolvimento sustentável e proteção do sistema climático, com princípios específicos como poluidor-pagador ou conservador-beneficiário.

As duas legislações estabelecem seus respectivos instrumentos de forma bastante correlata, contrariando o que cita Albuquerque (2012). No plano estadual, a governança deve se organizar por meio de um Fundo Estadual do Meio Ambiente e um Fundo Estadual de Recursos Hídricos; um Plano Estadual sobre Mudanças Climáticas (com os seguintes eixos estruturadores: mitigação; vulnerabilidade, impacto e adaptação; pesquisa e desenvolvimento; educação e divulgação); de mecanismos financeiros e econômicos, referentes à mitigação e à adaptação à mudança do clima (Biocrédito), que se conecta com os instrumentos definidos pela lei nacional; de um inventário de emissões; de sistemas de monitoramento e de padrões ambientais, estabelecendo-se metas quantificáveis.

Em suma, a governança do Estado do Paraná sobre as Mudanças Climáticas no período estudado (2012-2013), estava assim definida: Secretaria do Meio Ambiente e Recursos Hídricos (Sema), sob direção da Coordenadoria de Mudanças Climáticas e do Conselho Estadual de Mudanças Climáticas, com representantes do Poder Executivo estadual da área ambiental, de recursos hídricos e de desenvolvimento sustentável; da Assembleia Legislativa, dos municípios e entidades da sociedade relacionadas com os recursos hídricos. O Documento do Fórum Clima (2012) destaca na Lei estadual, os seguintes compromissos: prevê como objetivo o controle e a redução progressiva das emissões antrópicas por fontes e o fortalecimento das remoções antrópicas por sumidouros de gases de efeito estufa no território estadual (Art. $4^{\circ}$ ); prevê a criação de Fundo Estadual de Mudanças Climáticas (Femuc), a ser administrado pelo Conselho Estadual de Mudanças Climáticas, presidido pelo secretário estadual de Meio Ambiente e Recursos Hídricos (Art. $7^{\circ}$ ); e a criação do Selo Empreendedor Climático, destinado a organizações que comprovem a redução líquida de emissões por diminuição ou neutralização de emissões (Art. 14, § $3^{\circ}$ ).

Pode-se verificar, por meio de leitura atenta dos dois documentos para a governança das mudanças climáticas - o nacional e o estadual — que a PEMC-PR, no que tange aos conceitos técnicos com origem em compreensão científica, está em consonância com a política nacional, diferindo apenas em pequenos detalhes conceituais e naquilo que é peculiar a cada um dos entes federados, em especial com relação ao controle de emissões de GEEs e suas formas de compensação financeira, uma medida de mitigação. Ao priorizar a mitigação, a política estadual está de acordo com 
a visão de Viola et al.(2008), entendendo-se que as ações de mitigação podem constituir também possíveis ações de prevenção.

\section{METODOLOGIA: EXAMINANDO DOCUMENTOS, CHECANDO FONTES}

Os três municípios definidos como área de abrangência desse estudo, localizados na porção sudoeste da RMC - Curitiba, Fazenda Rio Grande e Araucária — em torno da Bacia do Alto Rio Iguaçu/PR, estão expostos aos riscos e vulnerabilidades socioambientais decorrentes das inundações; saneamento ambiental precário (disponibilidade hídrica, tratamento dos esgotos); ocupação das áreas de mananciais; geração e descarte de resíduos sólidos, entre outros fatores. Os três municípios apresentam características socioeconômicas bastante diversas entre si.

Para identificar, no âmbito da governança pública as ações de enfrentamento e mitigação aos desastres e perigos associados aos eventos climáticos extremos, que vêm sendo tomadas, a partir das instituições públicas desses municípios, bem como ações em âmbito estadual e federal, foram realizadas duas etapas de coleta de dados.

A primeira consistiu na análise de dados secundários obtidos em sites eletrônicos oficiais e documentos publicados por instituições públicas, além de aspectos legislativos nos âmbitos municipal, estadual e federal, pesquisados em uma série de instituições. Os dados e informações sobre cada instituição foram organizados em planilha Excel, embora nem todas as instituições pesquisadas façam parte das reflexões desse texto. A planilha foi dividida a partir das categorias: infraestrutura, legislação, aspectos gerenciais e financeiros, aspectos técnicos e científicos, formas de comunicação/ divulgação/educação ambiental. Essas categorias serviram para organizar as informações, de forma a se investigar as ações de enfrentamento aos desastres naturais e seus possíveis agravamentos em função das mudanças climáticas.

A segunda fase da pesquisa compreendeu um aprofundamento da identificação e análise das ações de algumas instituições: secretarias de Meio Ambiente e Defesa Civil municipais; Fórum de Mudanças Climáticas Globais e Secretaria Estadual de Meio Ambiente na escala estadual. Em cada instituição selecionada para a segunda fase foram realizadas entrevistas com representantes técnicos, para verificar sua narração sobre o ponto de vista institucional a respeito das questões examinadas evidenciadas nos seguintes pontos de abordagem: 1) Desastres Naturais em geral (ações preventivas e corretivas); 2) Mudanças climáticas (compreensão e importância do tema na instituição; identificação de problemas e consequências associadas; interesse e preparo da instituição sobre MC; preparo e apoio do governo; discussão do tema em outras instâncias municipais). A análise das informações documentais encontradas na primeira etapa, somada à análise das respostas obtidas nas entrevistas, permitem algumas conclusões sobre o estado da arte da governança pública nos três municípios em exame.

\section{INFORMAÇÕES E AÇÕES INSTITUCIONAIS SOBRE O ENFRENTAMENTO ÀS MUDANÇAS CLIMÁTICAS}

A análise das informações obtidas por meio de websites permitiu uma visão sobre como as instituições trabalham as ações de enfrentamento às mudanças climáticas anunciadas, além de uma primeira apreciação sobre o preparo do setor governamental com relação aos riscos e vulnerabilidades decorrentes dos eventos climáticos extremos, por meio de aspectos legislativos, de infraestrutura e/ou de gerenciamento.

Examinaram-se ainda as formas como ocorre a discussão interna dos aspectos relacionados às mudanças climáticas nessas instituições, concluindo-se que a divulgação de informações sobre as temáticas em exame são feitas principalmente por meio dos sites institucionais ou pela promoção de eventos e datas comemorativas. Segue-se em menor intensidade, a divulgação feita por meio dos 
bancos de dados, capacitações, material impresso (livros, boletins técnicos, cartilhas, artigos etc.) e publicação na mídia em geral. Vale salientar que a não ser nas instâncias específicas, como a Coordenação das Mudanças Climáticas e o Fórum da área, a questão é pouco discutida, não havendo um esforço maior para envolver os diferentes grupos representativos da comunidade no debate em torno da questão. Esta pouca inclusão dos diferentes atores sociais, envolvidos, evidenciada por meio dos sites governamentais consultados, é ainda mais acentuada nas instituições municipais.

No âmbito das instituições municipais, a análise das informações permite afirmar que o município de Curitiba, como já era previsto por sua condição de capital, encontra-se mais fortalecido em suas bases legais e institucionais, além de apresentar formas de divulgação mais ampla sobre o trato em relação os desastres naturais, do que os outros dois municípios. Destaca-se a atuação do Instituto de Pesquisa e Planejamento Urbano de Curitiba (Ippuc), que apresenta um nível de elaboração e implementação de políticas públicas muito superior ao dos outros municípios da RMC. Todavia, com exceção de ações de mitigação, realizadas em parceria, entre a Secretaria Municipal de Meio Ambiente (SMMA) com a Companhia de Habitação Popular de Curitiba (COHAB-CT) e a Defesa Civil municipal, voltadas à remoção, remanejamento ou reassentamento das famílias que habitam áreas de risco aos desastres naturais (enchentes, alagamentos, deslizamentos) no município, as demais secretarias, seguem o mesmo padrão de Araucária e Fazenda Rio Grande, ao apresentar apenas um potencial de enfrentamento que permitem ações preventivas ou corretivas, a depender de vontade política. (ARAUCÁRIA, 2013; CURITIBA, 2013; FRG, 2013). Ou seja, estes municípios possuem legislações (leis orgânicas e planos diretores) e infraestruturas mínimas que permitem promover ações de prevenção, de mitigação e adaptação, porém, dependem das prioridades estabelecidas por cada governo que assume a administração.

No âmbito estadual, pode-se inferir que a Secretaria Estadual do Meio ambiente (Sema) constitui, juntamente com a Defesa Civil do Paraná, é uma das instituições mais atuantes no que diz respeito a assuntos ligados às mudanças climáticas, atuando no âmbito legislativo, gerencial e de infraestrutura, além de coordenar uma série de programas voltados às questões ambientais.

A Defesa Civil Estadual concentra grande parte de suas ações ligadas às questões da prevenção e socorro a desastres naturais e/ou sinistros. Os programas principais desenvolvidos são: Bombeiro Comunitário; Sistema Integrado de Comando e Operações de Emergência (Sicoe); prevenção aos incêndios florestais; produtos perigosos e rede estadual de emergência de radioamadores. Possui ações de prevenção contra a influenza, primeiros socorros, de chuvas, de enchentes, de leptospirose e raios (DEFESA CIVIL PR, 2013). Saliente-se que o tema mudanças climáticas não aparece nos conteúdos coletados sobre a Defesa Civil.

Por seu turno, a análise das entrevistas com representantes das instituições em exame, aptos a responder sobre a temática em questão, permitiram captar o que se tem realizado em relação às ações de enfrentamento aos desastres naturais ocorridos na região e as perspectivas de ações frente às ameaças das mudanças climáticas.

Todos os entrevistados dos órgãos de Defesa Civil (um estadual e três municipais) declaram a realização de medidas preventivas aos riscos envolvidos, com destaque para treinamentos, palestras e contribuições para a formatação de políticas públicas ou planos de ação dos respectivos governos. As ações corretivas, no processo de mitigação, parecem ser aquelas que mais ocorrem: pelo conjunto de respostas, fica claro que estas ações ocorrem toda vez que há algum tipo de desastre, quando as defesas civis são chamadas, fazem o diagnóstico do problema e acionam diversas secretarias que se mobilizam para dar apoio às ações. Essas, quase sempre são de distribuição de kits de desastres, como telhas, plásticos, material de limpeza, entre outros, fornecidos pelos governos e roupas/utensílios quase sempre doados pela população. Outra ação comum é a remoção temporária das pessoas, das áreas de risco.

Quanto à infraestrutura e ao gerenciamento, pode-se afirmar que a Defesa Civil do Estado, que passa, em 2013/2014, por um processo de reestruturação, é a instituição que detém melhor estrutura 
para lidar com a questão dos desastres naturais. A Defesa Civil de Curitiba também possui estrutura que pode ser considerada adequada às suas finalidades; entretanto, as estruturas da Defesa Civil de Fazenda Rio Grande e Araucária são bastante precárias, trabalhando-se com condições mínimas.

Os representantes das secretarias municipais de Araucária e Fazenda Rio Grande, por sua vez, declaram que seus órgãos elaboram políticas públicas de ação de enfrentamento aos desastres naturais, o que foi confirmado por informações constantes nos sites, com destaque para atuação junto à Defesa Civil e remoção preventiva de populações de áreas de risco.

As ações preventivas são incipientes e precárias nos três municípios, reproduzindo a realidade nacional. Conclui-se que o que predomina são ações de enfrentamento de natureza mitigatória que ocorrem sempre que há desastres, predominando ações corretivas. Há apenas ações preventivas quando da remoção de populações de áreas de risco, não na dimensão necessária para prevenir novas catástrofes. A Defesa Civil Estadual é o órgão mais atuante em termos de prevenção, com treinamentos e elaboração de diretrizes que subsidiem leis e planos de contingência.

Segundo os entrevistados os principais desastres que ocorrem na região estudada são as inundações, chuvas fortes inclusive com granizo, vendavais, deslizamentos, ondas intensas de frio e/ou calor. As causas mais elencadas de riscos e perigos provocados por esses desastres estão relacionadas ao aumento da população e a ocupação de áreas de risco, ocasionada por uma urbanização desordenada, típica de áreas de periferização.

Alguns entrevistados, todos técnicos vinculados a órgãos governamentais, citam que, a partir do seu ponto de vista, as mudanças climáticas são as responsáveis pelo aumento dos desastres naturais, mas outros não estabelecem essa relação, numa proporção de 50\%. Ao se indagar se as suas instituições fazem correlação entre os desastres naturais locais e as mudanças climáticas, verifica-se basicamente uma divisão de opiniões: parte dos entrevistados afirma que em suas instituições predomina a visão das mudanças climáticas como causa dos problemas locais com desastres naturais, outros afirmam não conhecer, em suas instituições, tal correlação; alguns não entram no mérito da discussão. Essa divisão de opinião parece repercutir, entre os técnicos e gerentes, em âmbito local, o que ocorre na área científica, entre os que alertam sobre os perigos das mudanças climáticas com relação à intensificação dos eventos extremos e os que são céticos com relação às suas interrelações com esses eventos.

Com referência aos desastres naturais, todos os entrevistados admitiram que participam de eventos e/ou discutem sobre a questão dos desastres naturais e suas formas de prevenção/mitigação, contudo, em específico, sobre aquecimento global e mudanças climáticas, a maioria não observa e nem participa de discussões internamente. Apenas um entrevistado afirmou que "somente acompanha as discussões" e outros dois declararam que, de alguma forma, discutem sobre o assunto internamente. No site dos respectivos órgãos dos entrevistados verifica-se quase nenhuma discussão ou eventos relacionados ao tema. Entretanto, os entrevistados foram unânimes em afirmar que, se fossem confirmados os cenários do IPCC, os eventos climáticos extremos locais se intensificariam, em frequência de ocorrência e intensidade, causando vários prejuízos, com a necessidade de readequação urbana.

Em termos de legislação, antes das entrevistas, já se havia verificado que os três municípios têm legislações bastante consistentes em termos de prevenção — as respectivas leis orgânicas municipais e planos diretores garantem apoio à qualidade de vida de suas respectivas populações. Contudo, apenas a existência da legislação não oferece garantias, pois é preciso que a vontade política faça com que essas leis sejam cumpridas na íntegra. Muitas das ações previstas nem estão implementadas.

A maioria dos entrevistados afirmou que nem as instituições nem seus respectivos governos estão preparados para lidar com situações de agravamento de desastres em função das mudanças climáticas; alguns afirmaram que havia esse preparo, mas percebeu-se que foi uma resposta, sem respaldo, funcionando como discurso "politicamente correto". No entanto, todos admitiram que suas instituições estão "interessadas" na questão. 
Segundo a maioria dos entrevistados, o apoio dos governos "é pífio". Representantes de duas defesas civis mencionam que suas instituições só são lembradas quando ocorrem desastres. A Defesa Civil do Estado é a que tem recebido maior atenção do seu governo. Os apoios se caracterizam por treinamentos, apoio para obras de mitigação e recursos financeiros. Todos os entrevistados de instituições municipais admitiram que quando há desastres naturais locais há mobilização de diversos setores em apoio à solução de problemas imediatos. Questionados sobre se o tema em questão era discutido, por exemplo, nas Câmaras Municipais ou ONGs locais, todos disseram não ter conhecimento.

Embora esse trabalho se proponha a analisar realidades municipais, os dados coletados e as entrevistas realizadas no âmbito da Secretaria Estadual do Meio Ambiente foram decisivas para se compreender como a governança pública climática no Paraná, com suas imbricações municipais, está sendo organizada. As instituições que tratam desse processo de gestão e buscam seu gerenciamento no Estado e nos municípios são: a Secretaria Estadual do Meio Ambiente (Sema), por meio de sua Coordenadoria de Mudanças Climáticas (CMC) e o Fórum Paranaense de Mudanças Climáticas Globais, que funciona no âmbito dessa secretaria, emergindo como a única instituição na qual, de forma mais efetiva, pode ser observada alguma forma de participação direta da sociedade civil, por meio de representantes de segmentos específicos. O Conselho Estadual na área, que também poderia ter essa representação, embora de maneira mais técnica e mais fechada à participação, ainda não estava instalado durante o biênio 2012-2013.

O Fórum Paranaense de Mudanças Climáticas Globais foi o precursor das discussões desta temática no âmbito do Estado do Paraná, desde 2005, quando criado (regulamentado pela Lei n. 16.019 de 19 de dezembro de 2008). A partir desse Fórum, criou-se a Coordenadoria de Mudanças Climáticas (CMC), em 2007. Segundo os entrevistados da CMC, o Fórum resultou de uma demanda da sociedade. Pelo que se verificou, este coletivo pode ser considerado uma entidade de governança híbrida, mas com ênfase governamental; a representação da população em seu âmbito ainda é reduzida. Compõem o Fórum, representantes de diversas Secretarias e Conselhos Estaduais, da Casa Civil, da Coordenadoria Estadual de Defesa Civil, da Procuradoria Geral do Estado, do Ministério Público Estadual, de diversos institutos, universidades e companhias paranaenses, entre outros (http//: www.forumclima.pr.gov.br)

Entre 2005 e 2010, o Fórum organizou e participou de uma série de eventos, com um aumento crescente de ações (CHANG, 2012). Nesse período ocorreram divulgações importantes dos relatórios do IPCC, com forte repercussão na mídia nacional e o Fórum paranaense tentou discutir e repercutir os resultados desses relatórios em âmbito paranaense, tendo desenvolvido diversas ações, como eventos e debates. Segundo entrevistados da CMC, entre 2010 e 2012, porém, o Fórum apresentou atuação quase nula, causada por mudanças políticas geradas pela alternância do governo estadual. Esta é uma característica típica de governabilidade no Brasil, onde se assiste a falta de continuidade de políticas públicas, que deveriam ser transformadas em políticas de Estado. A troca de governos implica quase sempre na falta de continuidade à execução de políticas públicas e ações de desenvolvimento, o que poderia ser evitado por meio de maior engajamento e participação de representantes da sociedade civil. Somente em 2013, a CMC passou por reestruturação e novas ações foram programadas.

Apesar desse declínio em suas atividades no período registrado, na opinião dos entrevistados ligados ao coletivo, o fórum é o espaço onde mais se realiza um diálogo com a sociedade civil, é o ambiente propício para isso. Os entrevistados também assinalaram que existem questões e atribuições menores que são de responsabilidade da coordenadoria, mas é o fórum que faz um diálogo mais constante com o setor produtivo, com a sociedade civil organizada, então é um espaço mais democrático. O fórum é aglutinador de todo o processo sobre a governança das mudanças climáticas no estado.

Um dos aspectos que dificulta as ações na área, segundo um dos entrevistados, reside no fato de que a mudança climática não é visível, é intangível, então para se trabalhar com o princípio da 
precaução, exige-se um processo de educação continuada, não só na base — para ele, a educação ambiental sobre as mudanças climáticas constitui um processo que deve ir até terceira idade, porque é intangível, muito difícil de ser internalizada. Sendo assim, a falta de percepção real das mudanças climáticas, ainda muito pouco tangíveis no Paraná, e a falta de internalização dos seus conceitos e processos, por parte da sociedade, poderia estar contribuindo para a falta de posições políticas mais contundentes sobre a questão.

Dentre as ações que em andamento na CMC, durante o ano de 2013, destacam-se: Grupo de trabalho para regulamentar a Política Estadual de Mudanças Climáticas (cuja exigência por parte do Governo do Paraná é o alinhamento com a Política Nacional); formalização da coordenadoria em fase de regulamentação interna; utilização de dotação orçamentária para monitorar a qualidade do ar em Curitiba, Londrina e Maringá; preparação de sistema para monitoramento da indústria; revisão de resolução que estabelece critérios de qualidade do ar; preparação para realizar inventário de gases do efeito estufa; conclusão do diagnóstico de poluição veicular.

A Sema realiza o projeto "Estradas com Araucárias", em parceria com a Embrapa Florestas, para arborização de via rurais, especialmente com a espécie Araucária. Os próximos passos de atuação da CMC serão: diagnóstico dos gases de efeito estufa no Estado; planejamento estratégico para os próximos 20 anos, com um conjunto de programas, projetos e ações a serem estabelecidos; produção de cinco cartilhas educacionais para população geral a respeito do tema; elaboração de resolução para monitoramento dos gases do efeito estufa; formatação de um sistema de integrado de informações e parceria com a Secretaria de Planejamento e Sema; Elaboração do Plano Estadual de Poluição Veicular - renovação da frota, não adulteração, controle anual, mobilidade e construção de um plano de trabalho para o fórum; lançamento de menção que obriga determinados setores produtivos a fazer seus inventários de gás de efeito estufa, com solicitação de adesões e lançamento de selo certificador do inventário, a ser chancelado pelo Estado.

A Sema também está montando (2013-2014) um sistema de informação integrada de gestão ambiental do Estado com recursos do Banco Mundial (carimbados para Mudanças Climáticas). A Secretária da Agricultura e Abastecimento lidera um grupo de trabalho que se chama Programa Agricultura de Baixo Carbono, que se mobiliza também na questão das mudanças climáticas.

Segundo os entrevistados da CMC existem parcerias com outras secretarias, como a do Planejamento, com órgãos como IAP (Instituto Ambiental do Paraná) e IA (Instituto das Águas), sendo estes dois órgãos responsáveis por monitoramentos/fiscalizações e formação de Comitê Intersecretarial na área.

A participação dos municípios no processo se dará a partir de questionário a ser enviado às suas autoridades na área e pela sua representação no Fórum. Este último está implementando uma agenda de consecução da Política Estadual de MC, por meio de câmaras temáticas e grupos de trabalho (Educação Ambiental; Pesquisa e Política Climática). Além disso, trabalha na perspectiva de ação em duas frentes, a da mitigação e da adaptação, que abarcam ações de prevenção, não distinguindo assim os conceitos. Quanto ao setor industrial, pretende-se ampliar o sistema de controle nas indústrias, com atividades de fiscalização e monitoramento das emissões, com descentralização da rede de controle hoje estabelecida em Curitiba. Há um termo de cooperação entre a Sema e a Federação das Indústrias do Paraná (Fiep), que abrange não só mudanças climáticas, mas a todas as áreas ambientais.

Verifica-se também a partir das entrevistas que o processo burocrático interno do governo acaba emperrando o andamento das ações, que nunca fluem em um único órgão - há sempre a dependência dessa ou daquela secretaria, o que acaba atrasando e às vezes até deturpando o processo; um exemplo é o do Plano de Poluição Veicular que já foi entregue pela CMC, mas os processos que acompanham a manutenção e inspeção da frota continuavam, em 2013, em processo licitatório, moroso e complicado. Quando ocorre o processo de captação de recursos financeiros, há, muitas vezes, uma disputa entre as secretarias, com os recursos chegando diluídos, deixando de atender a contento as ações previstas. 
LIMA, M. D. V.; MACHADO, C. C. L.; ALVES, J. B.; FORTUNATO, R. A.

\section{CONSIDERAÇÕES FINAIS}

De forma geral, verifica-se que o Governo Estadual e a prefeitura de Curitiba possuem uma infraestrutura física e de pessoal maior e melhor preparada do que a dos municípios de Araucária e Fazenda Rio Grande para atuar no enfrentamento dos desastres naturais, sejam ou não causados pelas mudanças climáticas. Infere-se, assim, que tanto o suporte material como de recursos humanos são, salvo exceções, mais precários nas esferas governamentais municipais (excetuando-se o município que é capital) assim como são quase nulos o interesse e discussão sobre o tema nos dois municípios metropolitanos examinados, o que parece ser bastante contraditório, uma vez que, possivelmente, esses municípios por suas características inerentes ao fenômeno de periferização, seriam os mais vulneráveis em termos ambientais e populacionais com relação à ocorrências de fenômenos drásticos produzidos por uma potencial alteração climática. Um cenário de aumento de riscos nessa área incidiria, em especial sobre o município de Fazenda Rio Grande, que apresenta questões socioambientais e urbanas complexas, sendo o mais pobre dos três municípios.

Entretanto, nos três municípios as ações de enfrentamento aos desastres naturais ocorrem de maneira semelhante, predominado as ações corretivas, com poucas ações de prevenção/mitigação. Contudo, destaca-se que sempre que ocorrem desastres naturais, há uma mobilização intensa de apoio dos órgãos governamentais, em especial das defesas civis que respondem diretamente pelas primeiras ações a serem empreendidas.

Em relação à categoria de análise da governança do clima, no que se refere ao processo top down, de Viola et al, 2008, percebe-se, que as autoridades públicas parecem realizar algumas ações de enfrentamento e mitigação (mesmo que muito precárias), principalmente em Curitiba, como já citado, mas não primam por uma responsabilização mais ampla ou pela transparência, características do processo de governança, que deveria buscar sempre ganhar legitimidade junto à população. As formas de participação da sociedade não são estimuladas, conforme recomendam vários autores, apesar da existência de um Fórum na área, porém com representação social bastante limitada. De maneira ampla, a governança climática local parece ainda não se preocupar com a visão de Giddens (2010, p.279) de que sua função é a de "levar as pessoas a admitirem que os riscos sejam reais e prementes" e de "fomentar uma consciência mais generalizada da necessidade de ação". Esse fato pode ser confirmado em localidades dos municípios que, segundo relatos, apesar de algumas ações mitigatórias em curso com relação à ocorrência sazonal de inundações e as chuvas fortes, continua ocorrendo o aumento da população ocupando áreas de risco.

Aos olhos de alguns entrevistados, as questões relativas às mudanças climáticas são intangíveis e necessitam de processos e programas de educação continuada para que seja possível trabalhar o princípio da precaução. Há também questões burocráticas que dificultam a fluidez dos processos e o fato das ações de prevenção/mitigação serem menos intensas do que as ações corretivas emergenciais aumenta, sobremaneira, o estado de vulnerabilidade das comunidades afetadas.

As diversas reestruturações internas das instituições públicas durante as mudanças de governo e o reconhecido despreparo destas instituições para trabalharem os desastres e as mudanças climáticas, compõem ainda o quadro de evidências de que os processos e programas de Governança Pública Ambiental encontram-se em descompasso em relação ao anunciado ritmo acelerado dos eventos das mudanças climáticas, o que é, no mínimo, bastante preocupante para as sociedades locais e globais.

Ressalte-se mais uma vez, a prevalência das ações com potencial de enfrentamento de caráter corretivo em praticamente todas as instituições pesquisadas, em detrimento das ações de mitigação mais contundentes, preventivas e de adaptação, com algumas mais próximas ao termo ajustamento, tratado por Marandola (2009). Pode-se, inclusive, ir mais além: o economista equatoriano, crítico do neoliberalismo, Alberto Acosta (2013), na abertura do II Encontro Interdisciplinar de Comunicação Ambiental, realizado na Universidade Federal de Sergipe, em Aracaju, acrescentou às categorias teórico-práticas de enfrentamento - prevenção, mitigação, adaptação e ajustamento — a etapa que ele considera mais importante em um processo de governança de problemas socioambientais, 
a transformação. Ou seja, como transformar — pela comunicação, informação e educação na área ambiental - atitudes, comportamentos e hábitos da sociedade que redundem riscos e vulnerabilidades socioambientais, em especial, aqui neste artigo, aqueles de caráter gerador de alterações climáticas. Estas instâncias de transformação - comunicação, informação e educação —, embora citadas nas políticas públicas, ainda não emergiram como ações efetivas no conjunto de documentos e depoimentos sobre as políticas de enfrentamento às mudanças climáticas examinadas e merecem uma pesquisa específica.

Por fim, é preciso ainda, acentuar que o principal ponto destacado por autores como Pelling (2003), Pittock (2005), Renn (2008), Di Giulio e Ferreira (2014) é a ampliação da participação dos diversos atores da sociedade nos processos decisórios que envolvam a governança climática ou governança de riscos. Neste sentido, percebe-se que as políticas públicas, nacional e estadual na área, assim como as municipais aqui examinadas, são extremamente tímidas, não havendo, até o momento (2014), ações mais contundentes que possibilitem, por iniciativa e motivação governamental, a inserção de um leque de atores sociais que possam atuar de forma mais comprometida e, portanto, eficiente em um processo de prevenção e transformação diante de uma possível confirmação de efeitos causados por mudanças climáticas radicais.

\section{AGRADECIMENTO}

Este artigo constitui um dos resultados do projeto de pesquisa intitulado Mudanças climáticas globais e problemas do clima urbano: Desafios e cenários de adaptação e mitigação em face de riscos e vulnerabilidades socioambientais na RMC - Região Metropolitana de Curitiba/PR, financiado pelo MTCI-CNPQ (Processo 480271/2012-7), sob a coordenação geral do Prof Dr Francisco Mendonça (UFPR).

\section{REFERÊNCIA BIBLIOGRÁFICA}

ACOSTA, Alberto. Conferência de abertura. In: $2^{\mathbf{0}}$ Encontro Interdisciplinar de Comunicação Ambiental (Eica), 2013, Sergipe. Aracaju: Universidade Federal de Sergipe. In: http://licaufs.blogspot.fr/ Acesso em: 22 de outubro de 2013.

ALBUQUerQue, Laura. Análise Crítica das Políticas Públicas em Mudanças Climáticas e dos Compromissos Nacionais de Redução de Emissão de Gases de Efeito Estufa no Brasil. Rio de Janeiro: UFRJ/ COPPE, 2012. Dissertação de mestrado. In: $<$ http//: www.ppe.ufrj.br/ppe/production/tesis/laura_albuquerque.pdf $>$

ARAUCÁRIA. Site oficial da Prefeitura Municipal de Araucária. Disponível em $<$ http//: www.araucaria. pr.gov.br> Acesso em maio de 2013.

BARROS-PLATIAU, Ana Flávia; VARELLA, Marcelo Dias; SCHLEICHER, Rafael T., Meio ambiente e relações internacionais: perspectivas teóricas, respostas institucionais e novas dimensões do debate. Revista Brasileira de Política Internacional. 47(2); 2-32 (2004).

BECK, Ulrich. "A reinvenção da política: rumo a uma teoria da modernização reflexiva". In: BECK, U.; GIDDENS, A.; Lash, S. (orgs). Modernização reflexiva. São Paulo: Editora da Unesp, 1997, cap.1, 11-68p. BORSATO, Regiane. Governança ambiental e as certificações: participação e influência do movimento ambientalista nos instrumentos privados de gestão ambiental. Curitiba, 2012: Tese de doutorado (mimeo.). Universidade Federal do Paraná/PPPGMade.

BOSA, C. R.; LOMBARDI, D. C. G. Educação ambiental em área de regularização fundiária na cidade de Curitiba. REMOA.v.2, n.2, p. $241-261,2011$

BRASIL. Lei $\mathbf{n}^{\mathbf{1}}$ 12.187, De 29 De Dezembro de 2009. Institui a Política Nacional sobre Mudança do ClimaPNMC e dá outras providências. Disponível em:< http://www.planalto.gov.br/ccivil_03/_ato2007-2010/2009/ lei/112187.htm> Acessado em 09 de set 2013. 
LIMA, M. D. V.; MACHADO, C. C. L.; ALVES, J. B.; FORTUNATO, R. A.

CHANG, M. Estudo e mapeamento de vulnerabilidades a extremos climáticos no Estado do Paraná. RELATÓRIO DE PESQUISA DE PÓS-DOUTORADO. Rio de Janeiro. 2012. 102p.

COMEC. Site oficial da Coordenação da Região Metropolitana de Curitiba. Disponível em < http:// www.comec.pr.gov.br> Acesso em 22 de maio de 2014.

CURITIBA. Site oficial da Prefeitura Municipal de Curitiba. Disponível em < http://www.curitiba.pr.gov. br> Acesso em maio de 2013.

DEFESA CIVIL PR. Site oficial da Defesa Civil do Paraná. Disponível em < http://www.defesacivil. pr.gov.br> Acesso em maio de 2013.

DI GIULIO, Gabriela Marques e FERREIRA, Lúcia da Costa. Governança do risco: uma proposta para lidar com riscos ambientais no nível local. Curitiba, PR. Revista Desenvolvimento e Meio Ambiente: PPGMade/Editora da UFPR, v.28, jul./dez. 2013.

FÓRUM CLIMA. O desafio da harmonização das politicas públicas de mudanças climática. Em: $<$ http://www3.ethos.org.br/wp-content/uploads/2012/12/01_O-Desafio-da-Harmoniza\%C3\%A7\%C3\%A3o-das-Po1\%C3\%ADticas-P\%C3\%BAblicas-demMudan $\%$ C 3\%A 7 as-Clim $\%$ C3\%A 1 ticas-\%E2\%80\%93-F\%C3\%B3rum-Clima-abril-20121.pdf $>$.Acessado em: 20 de setembro de 2012.

FRANCISCO, D. P. Danos Socioambientais Urbanos em Curitiba: Uma Abordagem Geográfica. Revista RA'E GA, Curitiba, n. 9, p. 47-58, 2005. Editora UFPR.

FRG. Site oficial da Prefeitura Municipal de Fazenda Rio Grande. Disponível em < http://www.fazendariogrande.pr.gov.br> Acesso em maio de 2013.

FRITZSONS, E.; RIZZI, N.; BITTENCOURT, A. V.at. al. Estudo do impacto da contaminação por nitrogênio numa bacia hidrográfica cárstica. Curitiba. UPFR. Boletim Paranaense de Geociências, n. 49, p. 39-52, 2001.

GIDDENS, Anthony. A política da mudança climática. Rio de Janeiro: Zahar, 2010.

GIDDENS, Anthony. As consequências da modernidade. São Paulo: Editora Unesp, 1991.

HUMMEL, B. M. L. Desastres naturais e vulnerabilidades socioambientais: o caso de Curitiba. PR. 2009.135p. (Dissertação de Mestrado). Centro de Ciências Exatas e de Tecnologia. PUC-PR.

IPCC (2009). In: https://www.ipcc.ch/pdf/supporting-material/expert-meeting-detection-anthropogenic-2009-09.pdf

IPPUC. Site oficial do Instituto de Pesquisa e Planejamento Urbano de Curitiba. Disponível em < http:// www.ippuc.org.br> Acesso em maio de 2013.

LEFF, Enrique. Racionalidade ambiental: a reapropriação social da natureza. Rio de Janeiro, Civilização Brasileira, 2006.

LIMA, Myrian Del Vecchio. Gestão da coleta seletiva de resíduos em Curitiba: a estratégia das redes de comunicação em um processo de mobilização social. In. LIMA, Myrian Del Vecchio (Org.). Das urbanidades e ruralidades: conexões insustentáveis. 2008. p.59-84.

MARANDOLA Jr. Eduardo. “Tangenciando a vulnerabilidade”. In: HOGAN, Daniel J. e MARANDOLA Jr. E (orgs.): População e mudança climática: Dimensões humanas das mudanças ambientais globais. Campinas, SP: Núcleo de Estudos da População (Nepo), Unicamp; Brasília, UNFPA, 2009.

MASKREY, A. Comunidad y desastres em América Latina: estratégia de intervención. In: Lavell, A. (comp.). Vivendo em Riesgo: comunidads vulnerables y prevención de destares em América Latina. Colômbia: La Red/FLACSO. 1994.p 25-56.

MENDONÇA, Francisco. S.A.U. - Sistema socioambiental urbano: uma abordagem dos problemas socioambientais da cidade. IN: MENDONÇA, Francisco (org.) Impactos socioambientais urbanos. Curitiba: UFPR, 2004. 330p.

PARANÁ. Lei n.17.133/2012. Disponível em: <http://www.legislacao.pr.gov.br/legislacao /pesquisarAto. do? action=exibir\&codAto=67271\&indice=1\&totalRegistros $=22>$. Acessado em: 9 set 2013 .

PELLING, Mark. The Vulnerability of Cities: Natural Disasters and Social Resilience. London, UK: Earthscan Publications Ltda, 2003.

PINTO, Mônica Maria. Comunicação e educação em campanhas de enfrentamento e adaptação às mudanças climáticas. Curitiba, 2012: Dissertação de Mestrado (Mimeo.). Universidade Federal do Paraná/ 
PPGCom.

PITTOCK, A. Barrie. Climate change: turning up the heat. Australia: CSIRO Publishing, 2005.

RENN, O. Risk Governance: coping with uncertainty in a complex world. Londres: Earthscan, 2008.

SANTOS, Maria Helena de Castro. Governabilidade, governança e democracia: criação da capacidade governativa e relações executivo-legislativo no Brasil posConstituinte. In: DADOS - Revista de Ciências Sociais, Rio de Janeiro, volume 40, n. 3, 1997, pp. 335-376.

SANTOS, Milton. A urbanização brasileira. São Paulo: Hucitec, 1993.

SAUDE PR. Site oficial da Secretaria da Saúde do Paraná. Disponível em <http//: www.saude.pr.gov. br> Acesso em maio de 2013.

SEMA. Site oficial da Secretaria do Meio Ambiente e Recursos Hídricos. Disponível em < http//: www. meioambiente.pr.gov.br> Acesso em maio de 2013.

SOUSA SANTOS, Boaventura. Os processos da globalização. In: SOUSA SANTOS, Boaventura. A globalização e as ciências sociais. São Paulo: Cortez, 2005.

VEYRET, Yvette. Os riscos: o homem como agressor e vítima do meio ambiente. São Paulo: Contexto, 2007.

VIOLA, Eduardo; BARROS-PLATIAU, Ana Flávia; LEIS, Héctor. Governança e segurança climática na América do Sul. São Paulo: Instituto Fernando Henrique Cardoso; Santiago do Chile: Corporación de Estudios para Latinoamérica (Cieplan), 2008. 33 p. Contribuição ao projeto: “Uma Nova Agenda Econômica e Social para a América Latina”. Disponível em: <http//: www.ifhc.org.br/> e acessado em: 5 set. 2013.

Trabalho enviado em 18 de agosto de 2016 Trabalho aceito em 2 de setembro de 2016 